\title{
The association between race and gender, treatment attitudes, and antidepressant treatment adherence
}

\author{
Inger Burnett-Zeigler ${ }^{1}$, H. Myra Kim ${ }^{2,3}$, Claire Chiang ${ }^{2,4}$, Janet Kavanagh ${ }^{4}$, Kara Zivin ${ }^{2,4}$, Katherin Rockefeller ${ }^{4}$, \\ Jo Anne Sirey ${ }^{5}$ and Helen C. Kales ${ }^{2,4}$ \\ ${ }^{1}$ Department of Psychiatry and Behavioral Sciences, Northwestern University Feinberg School of Medicine, Chicago, IL, USA \\ ${ }^{2}$ Department of Veterans Affairs, HSR\&D Center for Clinical Care Management, and Serious Mental Illness Treatment, Resource and \\ Evaluation Center (SMITREC), Ann Arbor, MI, USA \\ ${ }^{3}$ Center for Statistical Consultation and Research, University of Michigan, Ann Arbor, MI, USA \\ ${ }^{4}$ Department of Psychiatry, University of Michigan, Ann Arbor, MI, USA \\ ${ }^{5}$ Weill Cornell Medical College, Department of Psychiatry, White Plains, NY, USA \\ Correspondence to: I. Burnett-Zeigler, PhD, E-mail: i-burnett-zeigler@northwestern.edu
}

Objectives: We examined the associations between treatment attitudes and beliefs with race-gender differences in antidepressant adherence.

Methods: Subjects $(n=186)$ were African-American and White subjects aged $\geq 60$ years, diagnosed with clinically significant depression, and had a new outpatient primary care recommendation for antidepressant treatment. Antidepressant adherence was assessed using the Brief Medication Questionnaire. Attitudes and beliefs were assessed using the Patients Attitudes Toward and Ratings of Care for Depression, two items rating perceived medication importance, and a modified version of the Stigma Scale for Receiving Psychological Help.

Results: African-American men and women had significantly greater concerns about antidepressants and significantly less understanding about treatment than White women. African-American men had significantly more negative attitudes toward healthcare providers than African-American and White women. African-American women were more likely than White men and women to endorse a medication other than their antidepressant as most important. Whereas some race-gender differences were found in personal spirituality, no group differences were found in perceived stigma. In a logistic regression model adjusted for key baseline variables, White women were significantly more adherent to antidepressants than African-American women $(\mathrm{OR}=3.05,95 \% \mathrm{CI}=1.06-8.81)$. Fewer concerns about antidepressants and indicating the antidepressant as the most important medication were both significantly associated with adherence. After including either of these two variables, the adherence difference between White women and African-American women was no longer significant $(\mathrm{OR}=2.56,95 \%$ $\mathrm{CI}=0.84-7.80)$.

Conclusions: Concerns about antidepressants and the importance of antidepressant medication are associated with adherence and are potentially modifiable through improved patient-provider communication, psycho-education, and therapeutic interventions. Copyright (C) 2013 John Wiley \& Sons, Ltd.

Key words: stigma; spirituality; race/ethnicity; antidepressant adherence

History: Received 13 December 2012; Accepted 17 April 2013; Published online 25 June 2013 in Wiley Online Library (wileyonlinelibrary.com)

DOI: 10.1002 /gps.3984

\section{Introduction}

Depression is common in older adults (Meeks et al., 2011, Thielke et al., 2010) and related to increased functional impairment, poorer quality of life, mortality due to physical illness, and suicide (Schulz et al., 2000, Rovner et al., 1991, Penninx et al., 2001, CroninStubbs et al., 2000, Gallo et al., 2008). Primary care physicians (PCPs) provide the majority of later-life depression treatment, particularly for African Americans 
(Luber et al., 2001, Areán et al., 2002, Neighbors et al., 2008). Antidepressants are often the evidence-based choice for older adults seen in primary care settings (Alvidrez and Areán, 2002); however, non-adherence is common, with estimates ranging from $40 \%$ to $75 \%$ (Pampallona et al., 2002). Racial differences in the use of antidepressant medications may exist, in that African-American patients find antidepressant treatment less acceptable (Cooper et al., 2003) and they are less likely to be taking antidepressants (Blazer et al., 2000) than White elders.

Models of health behaviors, such as the Theory of Reasoned Action (Ajzen, 1996), posit that behavioral intention (critical for treatment adherence) is determined by a person's weighing of potential risks and benefits of the behavior (Cooper et al., 2003, Van Voorhees et al., 2009). Zivin and Kales' adaptation (2008) of the Theory of Reasoned Action divides factors impacting health behaviors according to their potential modifiability by intervention as follows: (i) modifiable (beliefs and attitudes); (ii) potentially modifiable (e.g. psychiatric and medical comorbidity); and (iii) non-modifiable (gender and race). In our prior study (Kales et al., 2012), we examined the role of potentially modifiable and non-modifiable factors on antidepressant adherence and found that after controlling for demographic, illness, and functional status variables, there were significant differences in adherence between African-American and White older women. In the present study, we sought to examine the associations between the race-gender differences in adherence we previously found and attitudes and beliefs.

Older African Americans with depression report less favorable attitudes toward seeking treatment than older Whites, are more likely to express mistrust in mental health services, and believe that mental health treatment is not the most effective symptom reduction strategy (Conner et al., 2010). Past work among AfricanAmerican primary care patients found that concerns with antidepressant medication, such as side effects and potential for addiction, were extremely important considerations for depression care (Cooper et al., 2000) and that African Americans were less likely to view depression medication as beneficial (Kasckow et al., 2011).

Older adults may also prioritize physical health over mental health treatment. In a study of communitydwelling older adults who were asked to assess their life problems, $41 \%$ ranked physical health as their most important problem, whereas only $6 \%$ ranked depression as most important (Proctor et al., 2008); this study did not examine racial differences in the ranking of life problems. In the present study, we sought to examine if the treatment attitude that taking antidepressants was less important than medications for physical conditions was associated with race-gender differences in adherence.

Perceived stigma includes beliefs about the devaluation of and discrimination toward individuals with mental illness (Sirey et al., 2001b). There is an inverse relationship between perceived stigma and mental health treatment seeking (Brown et al., 2010, Conner et al., 2010, Cooper et al., 2003). High levels of perceived stigma have been significantly related to negative treatment attitudes in older African Americans (Conner et al., 2010). Sirey et al. found that high levels of perceived stigma at the start of treatment predicted early treatment discontinuation among older adults with major depression (Sirey et al., 2001a). However, there are limited data on how the relationship between stigma and adherence is affected by race.

There is some evidence to suggest that spiritual beliefs may also play a role in racial differences in antidepressant adherence. In a study of African-American older adults in primary care, Wittink et al. (2009) found that religious beliefs influenced how subjects conceptualized depression and how they engaged in treatment. Older African Americans conceptualized depression as a spiritual crisis characterized by a loss of faith. Regaining faith and participating religious activities such as prayer or attending church were identified as ways depression could be relieved (Wittink et al., 2009). African Americans have been found to rate personal or intrinsic spirituality among the most important aspects of depression care (Cooper et al., 2000, Cooper et al., 2001). There are limited data available on the relationship between spirituality and adherence, including the role of race-gender, in older adults.

In the present study of older adults with depression who were diagnosed in primary care settings and recommended antidepressant treatment, we examined treatment attitudes (including treatment concerns and prioritizing medications) and beliefs (including stigma and spirituality) as potentially associated with the racegender differences in antidepressant adherence found in our previous study (Kales et al., 2012). We hypothesized that poorer attitudes about treatment, greater concerns about stigma, and greater personal spirituality would account for these race-gender differences.

\section{Methods}

Subjects

This study used the same sample as the Kales et al. (2012) study. Subjects were recruited between March 
2007 and March 2010 from 13 primary care clinics located in Ann Arbor, Michigan and surrounding communities. Inclusion criteria were as follows: (i) adults aged 60 years and over; (ii) a diagnosis of clinically significant depression; (iii) seen in a participating primary care clinic; and (iv) a new recommendation for antidepressant treatment by the PCP. Clinically significant depression was defined as having the following: (i) a new antidepressant prescription from the PCP (encompassing newly diagnosed patients as well as patients with recurrent depression receiving a new antidepressant prescription for a current depressive episode) and (ii) a score of 5 or higher on the Geriatric Depression Scale-Short Form (Sheikh and Yesavage, 1986). Exclusion criteria included the following: (i) patients with active suicidal ideation, psychosis, a history of mania, or cognitive impairment ( $>3$ errors on the Six Item Screener (Callahan et al., 2002)); (ii) race other than White or African American; or (iii) the inability to communicate in English.

Subjects were directly referred to the study by their PCPs or identified through the electronic medical record. Our methods for identifying potential subjects using electronic medical records have been previously reported (Seyfried et al., 2009). After obtaining PCP consent, subjects were contacted by study staff and recruited via mail and telephone. The methods of this study were approved by the University of Michigan Medical School Institutional Review Board.

\section{Assessments}

Subjects were assessed at baseline and 4-month followup. The baseline interview assessed the following: (i) demographic variables including age, race, gender, marital status, and education; (ii) illness variables including past antidepressant use, number of prescribed medications, physical health status (SF-12 physical component scale), mental health status (SF-12 mental component scale) (Ware et al., 1996), comorbid anxiety (anxiety items of the Hospital Anxiety and Depression Scale (HADS-A) (Zigmond, 1983)), somatic anxiety (Anxiety Sensitivity Index-Revised (ASI-R); subscales pertaining to beliefs and fears about somatic sensations) (Deacon et al., 2003), and further assessment of depression using the Patient Health Questionnaire depression scale (Kroenke et al., 2001); (iii) functional assessment including instrumental (IADL) (Lawton and Brody, 1969) and basic (Katz ADL) (Katz, 1970) activities of daily living and executive function (Wechsler Letter-Number Sequencing subscale) (Wechsler, 1997); and (iv) attitudes and beliefs toward depression treatment including perceived stigma and personal spirituality. Attitudes toward depression care were assessed using a validated patient-centered instrument, the 30 -item Patients Attitude Toward and Ratings of Care for Depression (PARC-D) (Cooper et al., 2000). Each item on this instrument is scored on a 5-point Likert scale, with higher scores indicating more positive attitudes toward depression treatment and the prescribing physician. The PARC-D includes the following seven subscales: (i) Healthcare Providers' Interpersonal Skills; (2) Treatment Effectiveness; (3) Access; (4) Treatment Problems; (5) PCP Recognition of Depression; (6) Patient Education, Information, and Understanding; and (7) Intrinsic Spirituality. To explore patient attitudes about the importance of their depression medications, two items were included to assess which currently prescribed medications patients considered the two most important and the two least important, yielding three mutually exclusive groups: (i) those who consider antidepressant most important; (ii) those who consider antidepressant as least important; and (iii) those who consider medications other than antidepressants most important.

Perceived stigma was assessed using the Stigma Scale for Receiving Psychological Help, modified for depression treatment. Each item on this instrument is scored on a 4-point Likert scale (total scores range between 0 and 15) with higher scores indicating greater perceived stigma (Pyne et al., 2004).

\section{Adherence assessment}

The dependent variable for this study was a dichotomous indicator of antidepressant adherence (adherent/ non-adherent) at 4-month follow-up. Antidepressant adherence was assessed at 4 months, as the early treatment phase is a particularly critical time period with increased risk of treatment dropout, medication discontinuation (Sirey et al., 2001a, Sirey et al., 2001b), and vulnerability to suicide (Valenstein et al., 2009). Adherence was measured using the validated self-report adherence question from the Brief Medication Questionnaire (BMQ) (Svarstad et al., 1999) that asks how consistently the subject took their medication on a daily basis in the week prior to the interview. This item is significantly correlated with pharmacy refill records (Rickles and Svarstad, 2007). Consistent with prior studies that consider an antidepressant medication 
possession ratio of $\geq 80 \%$ to be adequate, we rated those as missing $0-1$ daily dose in a given week as adherent (Valenstein et al., 2002). Subjects who chose to never initiate the antidepressant medication by not filling the prescription or not ever taking the medication were considered non-adherent.

\section{Statistical analysis}

In our prior study (Kales et al., 2012), after adjusting for other covariates, we did not find race, gender, or an interaction of race by gender to be significantly associated with adherence. However, upon examining the antidepressant adherence difference across four race-gender subgroups, we found that White women were 3.1 times more likely than African-American women to be adherent to their antidepressant medication $(\mathrm{OR}=3.05,95 \% \mathrm{CI}=1.06-8.81, p=0.0389)$ even after adjusting for demographic characteristics, baseline illness, and function variables (but not for attitude-related variables). None of the other racegender pairs were significantly associated with adherence. Because of the significant differences in antidepressant adherence between White and African-American women in our previous study (Kales et al., 2012), in the present study, we examined the impact of attitudes and beliefs on adherence across four distinct race-gender subgroups (African-American women, African-American men, White women, and White men). Descriptive statistics were obtained for baseline characteristics, including attitudes and beliefs, by race-gender subgroups. Differences in baseline variables across the race-gender subgroups were assessed using analysis of variance or chi-square tests. We then performed logistic regression analysis with adherence as the dependent variable and race-gender subgroups as the primary predictors, adjusting for the baseline demographic, illness, and functional assessment variables. Next, we individually examined the associations between adherence and (i) perceived stigma, (ii) each of the seven subscales of PARC-D, and (iii) the medication importance groups. Lastly, we added the attitude and belief variables that were significant $(p<0.05)$ to the model with race-gender subgroups. Because $15 \%$ of subjects were missing partial data for at least one covariate such as anxiety, we applied a multiple imputation strategy using the MI procedure in SAS (SAS Institute Inc., Cary, NC) under a multivariate normal model that included all covariates as well as adherence. The logistic regression estimates were pooled across five imputation samples using Rubin's method (Rubin, 1987).

\section{Results}

\section{Sample characteristics}

The study included 198 adults aged $\geq 60$ years who were seen in primary care clinics, with diagnoses of clinically significant depression and newly recommended antidepressant treatment by their PCPs. Of these, 10 were lost to follow-up, and another 2 refused to answer the question concerning medication importance, leaving 186 participants. The 12 patients not included in these analyses did not differ significantly from the other 186 patients in education, marital status, or past antidepressant use. However, they were younger (63.6 vs. 67.3 years old, $p=0.0019$ ), less anxious (ASI-R total 38.0 vs. $51.8, p=0.0496$ ), less disabled (Katz ADL total 6.0 vs. $5.6, p<0.0001$; IADL 7.9 vs. $7.3, p<0.0001$ ), and had higher perceived stigma ( 8.5 vs. $6.9, p=0.0475$ ) and lower intrinsic spirituality (4.5 vs. $5.9, p=0.0258$ ). Table 1 displays complete demographic, illness, and function variables for the study sample.

\section{Determinants of antidepressant adherence}

Table 2 reports summary statistics of treatment attitudes and beliefs potentially associated with antidepressant adherence across the four race-gender subgroups. Noting only the significant difference at an overall $\alpha$ of 0.05 after adjusting for six multiple between race-gender subgroup comparisons, African-American women and men scored significantly lower than White women (corresponding to less positive attitudes) on attitude subscales that assessed concerns about antidepressants (Treatment Problems subscale) and understanding about treatment (Patient Education, Information, and Understanding). African-American men scored significantly lower than African-American and White women on attitudes toward health providers (Healthcare Providers' Interpersonal Skills), and African-American women were significantly less likely than White women and White men to indicate the antidepressant medication was their most important medication. African-American women had higher levels of intrinsic spirituality than White women and White men, and African-American men had higher levels of intrinsic spirituality than White women. No race-gender differences were found in attitudes regarding treatment effectiveness, access, and recognition of depression. No race-gender differences were found in perceived stigma.

Table 3 displays findings from logistic regression models predicting 4-month adherence using each of 
Table 1 Subjects' characteristics at baseline by race-gender groups

\begin{tabular}{|c|c|c|c|c|}
\hline & $\begin{array}{l}\text { AA women } \\
\quad(N=44)\end{array}$ & $\begin{array}{l}\text { AA men } \\
(N=37)\end{array}$ & $\begin{array}{l}\text { White women } \\
\qquad(N=57)\end{array}$ & $\begin{array}{l}\text { White men } \\
(N=48)\end{array}$ \\
\hline \multicolumn{5}{|l|}{ Age (years) } \\
\hline $60-64$ & $46 \%$ & $68 \%$ & $44 \%$ & $48 \%$ \\
\hline $65-74$ & $43 \%$ & $22 \%$ & $35 \%$ & $25 \%$ \\
\hline $75-90$ & $11 \%$ & $11 \%$ & $21 \%$ & $27 \%$ \\
\hline Education (high school or below) & $45 \%$ & $41 \%$ & $30 \%$ & $40 \%$ \\
\hline Marital status* (with partner/spouse) & $32 \%$ & $49 \%$ & $49 \%$ & $65 \%$ \\
\hline With prior depression treatment ${ }^{*}$ & $62 \%$ & $51 \%$ & $84 \%$ & $69 \%$ \\
\hline Seeing a therapist ${ }^{\star}$ & $5 \%$ & $35 \%$ & $16 \%$ & $12 \%$ \\
\hline Number of prescribed medications & 4.4 & 4.0 & 4.2 & 4.5 \\
\hline Short Form-36 Physical component summary (PCS) & 36.0 & 36.5 & 37.7 & 38.3 \\
\hline Short Form-36 Mental component summary (MCS) & 36.1 & 35.3 & 38.9 & 38.8 \\
\hline Depression score on Patient Health Questionnaire (PHQ) & 13.1 & 13.0 & 11.4 & 11.2 \\
\hline Hospital Anxiety and Depression Scale (HADS) & 8.7 & 9.9 & 9.5 & 8.6 \\
\hline Anxiety Sensitivity Index (ASI) ${ }^{\star}$ & 60.3 & 58.8 & 47.1 & 44.4 \\
\hline Katz index of independence in activities of daily living & 5.5 & 5.6 & 5.7 & 5.7 \\
\hline Instrumental activities of daily living scale (IADL) & 6.8 & 7.3 & 7.5 & 7.2 \\
\hline Weschler memory scale* & 6.8 & 7.8 & 10.4 & 8.6 \\
\hline
\end{tabular}

Cell values are means unless otherwise specified.

AA, African Americans.

${ }^{*} p<0.05$ for four-group comparison.

Table 2 Stigma, attitudes, and drug identified as most/least important by race-gender subgroups

\begin{tabular}{|c|c|c|c|c|}
\hline & $\begin{array}{l}\text { AA women } \\
(N=44)\end{array}$ & $\begin{array}{l}\text { AA men } \\
(N=37)\end{array}$ & $\begin{array}{l}\text { White women } \\
\qquad(N=57)\end{array}$ & $\begin{array}{l}\text { White men } \\
\quad(N=48)\end{array}$ \\
\hline Perceived stigma & 7.3 & 7.2 & 6.2 & 7.3 \\
\hline \multicolumn{5}{|l|}{ Attitude toward depression treatment and doctors } \\
\hline Intrinsic spirituality ${ }^{\mathrm{a}, \mathrm{c}, \mathrm{d}}$ & 6.9 & 6.6 & 5.0 & 5.6 \\
\hline Treatment problems $\mathrm{s}^{\mathrm{a}, \mathrm{d}}$ & 8.3 & 8.3 & 9.9 & 9.3 \\
\hline Treatment effectiveness & 12.4 & 12.1 & 12.7 & 12.1 \\
\hline Health providers' interpersonal skills ${ }^{b, d}$ & 22.0 & 20.2 & 22.9 & 21.4 \\
\hline Patient education, information, and understanding ${ }^{\mathrm{a}, \mathrm{d}}$ & 5.7 & 5.6 & 6.7 & 5.9 \\
\hline Access & 6.7 & 6.3 & 7.1 & 7.0 \\
\hline Recognition of depression & 7.8 & 7.1 & 7.8 & 7.6 \\
\hline \multicolumn{5}{|l|}{ Drugs identified as most/least important $(\%)^{a, c}$} \\
\hline$A D$ as most important & 6.8 & 24.3 & 35.1 & 31.3 \\
\hline$A D$ as least important & 18.2 & 16.2 & 19.3 & 16.7 \\
\hline Other drugs as most important & 75.0 & 59.5 & 45.6 & 52.1 \\
\hline
\end{tabular}

No differences were found in any of treatment attitude or belief variables between genders in Whites or between races in men.

${ }^{a}$ Indicates significant differences ( $p<0.05$ after adjusting for multiple comparison using Tukey's method) between African-American women versus White women.

${ }^{\mathrm{b}}$ African-American women versus African-American men.

cAfrican-American women versus White men.

${ }^{\mathrm{d}}$ White women versus African-American men.

treatment attitude and belief variables. Of the PARC-D subscales, those patients who endorsed fewer concerns with antidepressants (treatment problems) were more likely to be adherent $(\mathrm{OR}=1.27,95 \% \mathrm{CI}=1.06-1.52$, $p<0.01)$. Additionally, those who indicated that their antidepressant was the "most important" medication were significantly more likely to be adherent than those who indicated that their antidepressant was the "least important" medication (OR=4.96, 95\% $\mathrm{CI}=1.59-15.47, p<0.01)$. Perceived stigma was not significantly associated with antidepressant treatment adherence after adjusting for baseline covariates.

Independent of baseline demographic, illness, and functional status variables, the PARC-D Treatment Problems subscale (indicating antidepressant concerns) and the medication importance item were highly correlated with each other. Those who identified their antidepressant as the "most important" medication had fewer concerns about antidepressant treatment $(p<.01)$. Because of the high correlation 
Table 3 Covariate adjusted ${ }^{\mathrm{a}}$ odds ratio estimates based on logistic regression models for antidepressant adherence at 4-month follow-up

\begin{tabular}{|c|c|c|c|c|}
\hline Variable & $\operatorname{AOR}^{\mathrm{a}}(95 \% \mathrm{Cl})$ & $\mathrm{AOR}^{\mathrm{a}, \mathrm{b}}(95 \% \mathrm{Cl})$ & $\operatorname{AOR}^{\mathrm{a}}(95 \% \mathrm{Cl})$ & $\mathrm{AOR}^{\mathrm{a}}(95 \% \mathrm{Cl})$ \\
\hline \multicolumn{5}{|l|}{ Race $^{\mathrm{C}}$} \\
\hline AA women (reference) & 1.0 & & 1.0 & 1.0 \\
\hline AA men & $1.87(0.65-5.33)$ & & $2.03(0.68-6.05)$ & $1.64(0.56-4.84)$ \\
\hline White men & $2.29(0.81-6.50)$ & & $2.14(0.74-6.26)$ & $1.92(0.65-5.70)$ \\
\hline White women & $3.05(1.06-8.81)^{\star}$ & & $2.60(0.88-7.68)$ & $2.56(0.84-7.80)$ \\
\hline Stigma & & $0.95(0.82-1.09)$ & & \\
\hline \multicolumn{5}{|l|}{ Attitude } \\
\hline Intrinsic spirituality & & $0.84(0.70-1.00)$ & & \\
\hline Treatment problems & & $1.27(1.06-1.52)^{\star \star}$ & $1.26(1.04-1.51)^{\star}$ & \\
\hline Treatment effectiveness & & $1.08(0.94-1.25)$ & & \\
\hline Health providers' interpersonal skills & & $1.12(0.99-1.25)$ & & \\
\hline Patient education, information, and understanding & & $1.14(0.92-1.41)$ & & \\
\hline Access & & $1.15(0.95-1.39)$ & & \\
\hline Recognition of depression & & $1.24(0.97-1.59)$ & & \\
\hline \multicolumn{5}{|l|}{ AD importance } \\
\hline AD least important (reference) & & 1.0 & & 1.0 \\
\hline AD most important & & $4.96(1.59-15.47)^{\star *}$ & & $4.48(1.40-14.30)^{*}$ \\
\hline Other drugs most important & & $1.70(0.68-4.23)$ & & $1.87(0.72-4.80)$ \\
\hline
\end{tabular}

AA, African American; AOR, adjusted odds ratio; CI, confidence interval.

${ }^{a}$ Adjusted for demographic variables of age, marital status, and education, whether seeing a therapist, illness burden variables of prior treatment of depression, number of prescribed medications, physical component summary score (PCS), mental component summary score (MCS), depression score on Patient Health Questionnaire (PHQ total), Hospital Anxiety and Depression score (HADS total), and Anxiety Sensitivity Index (ASI total), and for functional status variables of Katz index of independence in activities of daily living (Katz total), instrumental activities of daily living (IADL total), and Weschler memory scale, all assessed at baseline.

${ }^{\mathrm{b}} \mathrm{AOR}$ estimates for stigma, each of the seven attitude subscales, and the three levels of $\mathrm{AD}$ importance were based on fitting separate logistic regression models to assess their individual effect independent of the baseline demographic variables, illness burden variables, and functional status variables. ${ }^{a}$

${ }^{c}$ Post-hoc contrasts also showed that the ORs were 1.23 for White men versus Black men (95\% CI 0.44-3.43), 1.63 for White women versus Black men (95\% CI 0.57-4.66), and 1.33 for White women versus White men (95\% CI 0.52-3.41).

${ }^{*} p<0.05$.

${ }^{* *} p<0.01$.

between the two measures, we added them each in a separate logistic regression model with race-gender subgroups, adjusting for baseline demographic, illness, and functional variables. In the first model, the Treatment Problems subscale remained significantly associated with adherence $(\mathrm{OR}=1.26,95 \% \mathrm{CI}=1.04-1.51)$; in the second model, indicating the antidepressant as most important medication also remained significantly associated with adherence $(\mathrm{OR}=4.48,95 \%$ $\mathrm{CI}=1.40-14.30$ ). Further, after inclusion of either of the two variables, the adherence disparity between White and African-American women was no longer statistically significant.

\section{Discussion}

Our previous study found race-gender differences in antidepressant adherence among older primary care patients (Kales et al., 2012). In the present study, we examined treatment attitudes and beliefs as a potential explanation for race-gender differences in antidepressant adherence. African-American men and women expressed greater concerns about treatment problems and less understanding about treatment than White women, and African-American men expressed significantly more negative attitudes toward health providers than White and African-American women. AfricanAmerican women were significantly less likely than White men and women to endorse their antidepressant as their most important medication. Fewer concerns about treatment problems and indicating the antidepressant as the most important medication remained significantly associated with adherence in adjusted models. When treatment problems and medication importance were examined in logistic regression models with race-gender group indicators, each remained significantly associated with adherence, after controlling for baseline covariates. However, the disparity between White and African-American women was no longer statistically significant, suggesting that these attitudes may have accounted for the racegender differences found in the previous study.

The Treatment Problems subscale was the only PARC-D subscale that was significantly associated with antidepressant adherence. Subjects who endorsed concerns related to antidepressants were less likely to be adherent to antidepressants. This is consistent with 
past work among African-American patients finding that concerns about antidepressants such as side effects and addiction potential were extremely important to patients (Cooper et al., 2000). Providing patients with accurate information about the risks and benefits of antidepressant use may allay some of these concerns and could potentially improve antidepressant adherence.

Patients who considered antidepressants to be their "most important" medication were significantly more likely to be adherent than patients who considered antidepressants to be the "least important." AfricanAmerican women were significantly less likely to rank their antidepressant medication as most important compared with the other race-gender groups. Our finding that the majority of older adults in primary care do not consider their antidepressants as their most important medication is consistent with prior research (Proctor et al., 2008). Patients may view their antidepressant use as less necessary than taking their other medications for "medical" conditions resulting in antidepressant non-adherence, potentially viewing their antidepressant use as "discretionary." While prioritizing medications for "medical" conditions may be rational for patients with severe disease (for example, extremely low cardiac output), our findings indicate that it may also be a predictor of antidepressant nonadherence, particularly in African-American women.

Some patients may also consider antidepressants a less important medication because they believe they have other options for coping with their symptoms (psychotherapy, religious practices, and social support). Although antidepressant treatment is often the evidence-based choice for older adults seen in primary care settings, psychotherapy may be the preferred choice (Gum et al., 2006, Raue et al., 2009, van Schaik et al., 2004). In this study, $19 \%$ of African Americans and $14 \%$ of Whites reported that they were seeing a therapist at baseline; however, among those who were non-adherent at 4 months, only four African Americans and three Whites reported seeing a therapist, and we did not find seeing a therapist to be significantly associated with 4-month adherence (results not shown). Future studies should investigate whether patients who consider their antidepressants less important cope with their depression symptoms in other ways.

Although we found that older African Americans endorsed significantly greater personal spirituality than White subjects, after controlling for other variables, personal spirituality was not associated with adherence. Prior work has found that African Americans are significantly more likely than White subjects to rate intrinsic spirituality as an important component of depression care (Cooper et al., 2001). It is unclear if spirituality serves as a barrier to effective depression care, such as treatment adherence among AfricanAmerican patients (Cooper et al., 2003). Some studies have suggested an association between religious participation and improved treatment participation and depression outcomes in the older adults (Wittink et al., 2009, Bosworth et al., 2003, Koenig, 1998). The relationship between spirituality and adherence is complex and merits further study.

We also did not find perceived stigma to be significantly associated with race-gender differences in adherence. Another facet of stigma is internalized stigma, which refers to the devaluation, shame, and secrecy triggered by applying negative stereotypes associated with mental illness to oneself (Corrigan and Penn, 1999). Although we did not examine mediation in the present study, recent work (Conner et al., 2009, Brown et al., 2010, Conner et al., 2010) has found internalized stigma to partially mediate the relationship between attitudes and treatment in older AfricanAmerican subjects.

The main adherence differences found were between African-American and white women. The relationship between adherence and race-gender has received relatively little focus to date. Conventional wisdom holds that women are more willing to engage in depression treatment than men, but this may hold up less well in non-White populations. Previous work describing greater rates of prior treatment and current antidepressant use among women as compared with men may have come from predominately White samples (Kales et al., 2012). The finding of the lowest adherence rates among African-American women clearly merits further study, particularly given the association with potentially modifiable attitudes found here.

This study has several limitations. The sample was recruited from primary care clinics in southeastern Michigan; results may not be generalizable to other geographic areas. Although we used a well-validated self-report measure (BMQ) to examine adherence, electronic monitoring or pill counts may have yielded more precise results (Unützer et al., 1997). Lastly, we did not measure internalized stigma; a greater relationship between stigma and adherence may have been found had we done so.

This study provides important new information about attitudes and beliefs related to antidepressant adherence. Attitudes are potentially modifiable through improved patient-provider communication and culturally sensitive psycho-education and therapeutic interventions that could include the following: (i) discussing concerns related to antidepressants such 
as worries about side effects or addiction; (ii) providing easy to understand educational materials; or (iii) utilizing motivational enhancement techniques, such as conducting decisional balances. Future research should further explore adherence in AfricanAmerican women, other treatment attitudes and beliefs that may be related to poor adherence, the relationship between the multiple dimensions of stigma and antidepressant adherence, and innovative ways in which alternative coping strategies such as religious practices, social support, and psychotherapy may be used to improve antidepressant adherence.

\section{Conflict of interest}

None declared.

\section{Key points}

- African Americans expressed greater concerns about treatment problems including possible side effects associated with depression treatment and less understanding about depression treatment than White female subjects.

- African-American women were less likely to endorse their antidepressant as being their most important medication as compared with White female and White male subjects.

- Concerns about treatment problems and medication importance were associated with race-gender differences in adherence.

\section{Acknowledgements}

Contributors: The authors gratefully acknowledge the participating subjects and physicians.

Funders: This research was supported by a grant from the National Institute of Mental Health, 5R21MH073002. The funding organization had no role in any of the following: design and conduct of the study; collection, management, analysis, and interpretation of the data; and preparation, review, or approval of the manuscript.

\section{References}

Ajzen I. 1996. The directive influence of attitudes on behavior. In The Psychology of Action: Linking Cognition and Motivation to Behavior, Gollwitzer PM, Bargh JA (eds.). Guilford Press: New York, NY US.

Alvidrez J, Areán PA. 2002. Physician willingness to refer older depressed patients for psychotherapy. Int J Psychiatry Med 32: 21-35.
Areán PA, Alvidrez J, Barrera A, Robinson GS, Hicks S. 2002. Would older medical patients use psychological services? Gerontologist 42: 392-398.

Blazer DG, Hybels CF, Simonsick EM, Hanlon JT. 2000. Marked differences in antidepressant use by race in an elderly community sample: 1986-1996. Am J Psychiatry 157: 1089-1094.

Bosworth HB, Park KS, Mcquoid DR, Hays JC, Steffens DC. 2003. The impact of religious practice and religious coping on geriatric depression. Int J Geriatr Psychiatry 18: 905-914.

Brown C, Conner KO, Copeland VC, Grote N, Beach S, Battista D, Reynolds CF. 2010. Depression stigma, race, and treatment seeking behavior and attitudes. J Community Psychol 38: 350-368.

Callahan CM, Unverzagt FW, Hui SL, Perkins AJ, Hendrie HC. 2002. Six-item screener to identify cognitive impairment among potential subjects for clinical research. Medical Care 40: 771-781.

Conner KO, Copeland VC, Grote NK, Koeske G, Rosen D, Reynolds CF, III, Brown C. 2010. Mental health treatment seeking among older adults with depression: the impact of stigma and race. Am J Geriatr Psychiatry 18: 531-543.

Conner KO, Koeske G, Brown C. 2009. Racial differences in attitudes toward professional mental health treatment: the mediating effect of stigma. J Gerontol Soc Work 52: 695-712.

Cooper LA, Brown C, Vu HT, Ford DE, Powe NR. 2001. How important is intrinsic spirituality in depression care? A comparison of White and African-American primary care patients. J Gen Intern Med 16: 634-638.

Cooper LA, Brown C, Vu HT, Palenchar DR, Gonzales JJ, Ford DE, Powe NR. 2000. Primary care patients' opinions regarding the importance of various aspects of care for depression. Gen Hosp Psychiatry 22: 163-173.

Cooper LA, Roter DL, Johnson RL, Ford DE, Steinwachs DM, Powe NR. 2003. Patient-centered communication, ratings of care, and concordance of patient and physician race. Ann Intern Med 139: 907-915.

Corrigan PW, Penn DL. 1999. Lessons from social psychology on discrediting psychiatric stigma. Am Psychol 54: 765-76.

Cronin-Stubbs D, Mendes De Leon CF, Beckett LA, Field TS, Glynn RJ, Evans DA. 2000. Six-year effect of depressive symptoms on the course of physical disability in community living older adults. Arch Intern Med 160: 3074-3080.

Deacon BJ, Abramowitz JS, Woods CM, Tolin DF. 2003. The Anxiety Sensitivity Index-Revised: psychometric properties and factor structure in two nonclinical samples. Behav Res Ther 41: 1427-1449.

Gallo JJMDMPH, Morales KS, Post EMDP, Bogner HMDM, Lin JP, Bruce MPMPH. 2008. The effect of a primary care practice-based depression intervention on mortality in older adults. Ann Intern Med 148: 245.

Gum AM, Areán PA, Hunkeler E, Tang L, Katon W, Hitchcock P. Steffens DC, Dickens J, Unützer J. 2006. Depression Treatment Preferences in Older Primary Care Patients. The Gerontologist 46: 14-22.

Kales HC, Nease D, Sirey JA, Zivin K, Kim HM, Lynn S, Chiang C, Valenstein M, Neighbors HW, Blow FC. 2012. Racial differences in adherence to antidepressant treatment in later life. Am J Geriatr Psychiatry.

Kasckow J, Ingram E, Brown C, Tew JD JR, Conner K, Morse JQ, Haas GL, Reynolds C, Oslin D. 2011. Differences in treatment attitudes between depressed African-American and Caucasian veterans in primary care. Psychiatr Serv 62: 426-429.

Katz S. 1970. Progress in development of the index of ADL. Gerontologist 10: 20-30.

Koenig HG. 1998. Religious attitudes and practices of hospitalized medically ill older adults. Int J Geriatr Psychiatry 13: 213-224.

Kroenke K, Spitzer RL, Williams JBW. 2001. The PHQ-9: validity of a brief depression severity measure. J Gen Intern Med 16: 606-613.

Lawton MP, Brody EM. 1969. Assessment of older people: self-maintaining and instrumental activities of daily living. Gerontologist 9: 179-186.

Luber MP, Meyers BS, Williams-Russo PG, Hollenberg JP, Didomenico TN, Charlson ME, Alexopoulos GS. 2001. Depression and service utilization in elderly primary care patients. Am J Geriatr Psychiatry 9: 169-176.

Meeks TW, Vahia IV, Lavretsky H, Kulkarni G, Jeste DV. 2011. A tune in "a minor" can "b major": a review of epidemiology, illness course, and public health implications of subthreshold depression in older adults. J Affect Disord 129: 126-142.

Neighbors HW, Woodward AT, Bullard KM, Ford BC, Taylor RJ, Jackson JS. 2008. Mental health service use among older African Americans: the National Survey of American Life. Am J Geriatr Psychiatry 16: 948-956.

Pampallona S, Bollini P, Tibaldi G, Kupelnick B, Munizza C. 2002. Patient adherence in the treatment of depression. Br J Psychiatry 180: 104-109.

Penninx BWJH, Beekman ATF, Honig A, Deeg DJH, Schoevers RA, Van Eijk JTM, Van Tilburg W. 2001. Depression and cardiac mortality: results from a community-based longitudinal study. Arch Gen Psychiatry 58: 221-227.

Proctor EK, Hasche L, Morrow-Howell N, Shumway M, Snell G. 2008. Perceptions about competing psychosocial problems and treatment priorities among older adults with depression. Psychiatr Serv 59: 670-675.

Pyne JMMD, Kuc EJMD, Schroeder PJBS, Fortney JCP, Edlund MMDP, Sullivan GMDM. 2004. Relationship between perceived stigma and depression severity. J Nerv Ment Dis 192: 278-283.

Raue PJ, Schulberg HC, Heo M, Klimstra S, Bruce ML. 2009. Patients' depression treatment preferences and initiation, adherence, and outcome: A randomized primary care study. Psychiatric Services 60: 337-343. 
Rickles NM, Svarstad BL. 2007. Relationships between multiple self-reported nonadherence measures and pharmacy records. Res Social Adm Pharm 3: 363-377. Rovner B, German P, Brant L, Clark R, Burton L, Folstein M. 1991. Depression and mortality in nursing homes. J Am Med Assoc 265: 2672.

Rubin DB. 1987. Multiple imputation for nonresponse in surveys. In Wiley Series in Probability and Mathematical Statistics. Applied Probability and Statistics. Wiley: New York.

Schulz R, Beach SR, Ives DG, Martire LM, Ariyo AA, Kop WJ. 2000. Association between depression and mortality in older adults: the Cardiovascular Health Study. Arch Intern Med 160: 1761-1768.

Seyfried L, Hanauer DA, Nease D, Albeiruti R, Kavanagh J, Kales HC. 2009. Enhanced identification of eligibility for depression research using an electronic medical record search engine. Int J Med Inform 78: e13-e18.

Sheikh J, Yesavage J. 1986. Geriatric Depression Scale (GDS): recent evidence and development of a shorter version. In Clinical Gerontology: A Guide to Assessment and Intervention. The Haworth Press: New York.

Sirey JA, Bruce ML, Alexopoulos GS, Perlick DA, Friedman SJ, Meyers BS. 2001a. Stigma as a barrier to recovery: perceived stigma and patient-rated severity of illness as predictors of antidepressant drug adherence. Psychiatr Serv 52: 1615-1620.

Sirey JA, Bruce ML, Alexopoulos GS, Perlick DA, Raue P, Friedman SJ, Meyers BS. $200 \mathrm{lb}$. Perceived stigma as a predictor of treatment discontinuation in young and older outpatients with depression. Am J Psychiatry 158: 479-481.

Svarstad BL, Chewning BA, Sleath BL, Claesson C. 1999. The brief medication questionnaire: a tool for screening patient adherence and barriers to adherence. Patient Educ Couns 37: 113-124.

Thielke SM, Diehr P, Unützer J. 2010. Prevalence, incidence, and persistence of major depressive symptoms in the cardiovascular health study. Aging Ment Health 14: 168-176.
Unützer J, Patrick DL, Simon G, Grembowski D, Walker E, Rutter C, Katon W. 1997. Depressive symptoms and the cost of health services in HMO patients aged 65 years and older. JAMA 277: 1618-1623.

Valenstein M, Copeland LA, Blow FC, Mccarthy JF, Zeber JE, Gillon L, Bingham CR, Stavenger T. 2002. Pharmacy data identify poorly adherent patients with schizophrenia at increased risk for admission. Medical Care 40: 630-639.

Valenstein M, Kim HM, Ganoczy D, Mccarthy JF, Zivin K, Austin KL, Hoggatt K, Eisenberg D, Piette JD, Blow FC, Olfson M. 2009. Higher-risk periods for suicide among VA patients receiving depression treatment: prioritizing suicide prevention efforts. J Affect Disord 112: 50-58.

Van Schaik DJF, Klijn AFJ, Van Hout HPJ, Van Marwijk HWJ, Beekman ATF, De Haan M, Van Dyck R. 2004. Patients' preferences in the treatment of depressive disorder in primary care. General Hospital Psychiatry 26: 184-189.

Van Voorhees BW, Paunesku D, Fogel J, Bell CC. 2009. Differences in vulnerability factors for depressive episodes in African American and European American adolescents. J Natl Med Assoc 101: 1255-1267.

Ware JEJP, Kosinski MM, Keller SDP. 1996. A 12-item Short-Form Health Survey: construction of scales and preliminary tests of reliability and validity. Medical Care 34: $220-233$.

Wechsler D. 1997. WMS-III: Wechsler memory scale administration and scoring manual. Psychological Corp.

Wittink MN, Joo JH, Lewis LM, Barg FK. 2009. Losing faith and using faith: older African Americans discuss spirituality, religious activities, and depression. J Gen Intern Med 24: 402-427.

Zigmond ASARPS. 1983. The hospital anxiety and depression scale. Acta Psychiatr Scand 67: 361-370. 